\title{
Percepción del apoyo familiar en los consumidores de drogas y su relación con trastornos psiquiátricos
}

\section{Perception of family support in dependents of alcohol and others drugs: relationship with mental disorders}

\author{
Makilim Nunes Baptista*; ValdiR de Aquino Lemos ${ }^{* *}$; \\ Adriana Munhoz Carneiro*; Paulo Rogério \\ MORAIS
}

*Universidade São Francisco - USF/Itatiba/São Paulo/Brasil.
${ }^{\star \star}$ Universidade Federal de São Paulo -UNIFESP/São Paulo/Brasil.
${ }^{\star \star \star ~ U n i v e r s i d a d e ~ F e d e r a l ~ d e ~ R o n d o ̂ n i a ~ U N I R ~-~ P o r t o ~ V e l h o ~ / R O ~ / ~ B r a s i l . ~}$
Enviar correspondencia a:
Makilim Baptista
Rua Alexandre Rodrigues Barbosa, 45, Centro, Itatiba -
SP/Brasil/ 13251-900
e- mail: makilim01@gmail.com.br

\section{Resumen}

Este estudio tuvo como objetivo analizar las relaciones entre la percepción del apoyo familiar, los sintomas depresivos, ansiedad y desesperanza en las personas dependientes de alcohol o drogas (AOD). Participaron de este estudio 97 pacientes en tratamiento, de edades comprendidas entre 18 y 58 años, de ambos sexos de seis instituciones privadas para el tratamiento de la drogodependencia, ubicado en Santos - SP / Brasil. Los participantes respondieron al Inventario de Percepción de Apoyo a la Familia, IPSF, el Inventario de Depresión de Beck-BDI, el Inventario de Ansiedad de Beck, BAl, Escala de Desesperanza - Beck y criterios para el abuso o dependencia de sustancias en el DSM-IV TR. Los resultados indican la existencia de correlaciones negativas entre el apoyo familiar percibido y los niveles de depresión, ansiedad y desesperanza. En la muestra estudiada, el apoyo familiar resultó ser un factor como una variable condicionada por los niveles de ansiedad y depresión. Estos resultados indican que la percepción del apoyo familiar puede ser un importante apoyo social para el paciente con AOD.

Palabras claves: ansiedad; depresión; suporte familiar; desesperanza; transtornos relacionados con substancias.

\section{Abstract}

The present article aimed to analyze the relationships between perception of family support, levels of depression, anxiety and hopelessness in alcohol or drug dependent patients (AOD). Participated of this study 97 patients under treatment, aged between 18 and 58 years, of both genders from six private institutions for treatment of drug dependency, located in Santos - SP/Brazil. Participants responded to the Inventory of Perceived Family Support- IPSF, the Beck Depression Inventory-BDI, Beck Anxiety InventoryBAI, Hopelessness Scale - BHS and Criteria for substance abuse or dependence at DSM-IV TR. Results indicated negative correlations between perceived family support and levels of depression, anxiety and hopelessness. Moreover, family support proved to be a conditional variable for levels of anxiety and depression. These results indicated that the perception of family support may be an important social support for the patient with AOD.

Key words: anxiety; depression; family support; hopelessness; substancerelated disorders. 
$\mathrm{F}$ mily and its structures has been considerably changing over the course of the years (Brasileiro, Jablonski \& FéresCarneiro, 2002), and has been pointed as a factor related with substance use (Chen, 2010; Paiva \& Ronzani, 2009; Tang et al., 2010). In some studies, family appears as a protective factor, contributing to feelings of security, affection, comfort, protection, care, interest and empathy (Herman \& Petersen, 1996; McFarlane, Belissimo \& Norman, 1995). Other factors identified as protective for drug use are the quality of the relationships between family members, rules and boundaries, supervision and monitoring, negotiation, good financial resources and communication (Cronkite \& Moos, 1984; Hanson \& Chen, 2007; Weisner, 1993). Moreover, family might act as a risk factor when related to neglected families, poor communication between family members and lack of rules (Herman \& Petersen, 1996; Botella, 2007; Pardo, Pineda, Carrillo \& Castro, 2006; Kumpfer, Alvarado \& Whiteside, 2003; Rodriguez, 2003; Hawkin, Arthur \& Catalano, 1998).

A research with addicted people observed that family is reported as a protective factor on the engagement of users in the treatment for addiction (Schenker \& Minayo, 2004). A systematic review reported that the rate of involvement with drugs is lower among teenagers who received greater parental monitoring (Paiva \& Ronzani, 2009). It was also found that parenting styles classified as "authoritative" and "non permissive" are related to lower consumption of psychotropic drugs, alcohol, tobacco and other drugs, while "neglected" is associated with greater consumption of psychotropic drugs, so that the most neglected the children are, and the more inadequate the family is, the greater risk for children to become involved in drug abuse.

A research based on interviews with mothers whose sons were monitored due to drug abuse corroborates this hypothesis. A response analysis was performed and answers were categorized in "family helpless" containing information about the parental relationship, and "community help", with answers about support, acceptance and family structure. Results showed that interviewees pointed out family conflicts as possible explanations for their need for drugs (such us, parental drug use, need for approval and family affection and neglecting), as difficulties in dealing with their own emotional problems, conflicts and lack of family rules (Hermeto, Sampaio \& Carneiro, 2010).

A study about the interference of gender in the sense of coherence, perceived social support and negative emotions was performed amongst 199 Israeli inmates with drug abstinence from a maximum security penitentiary. Among the participants, 65 were males, and $16 \%$ of the men were divorced and $41 \%$ married, while $37 \%$ of women were divorced and 15\%, married. They met the DSM IV criteria for Drugs Dependence and answered scales to access perceived social support from family and friends, coherence and state of anxiety. Findings indicated differences between perceptions of family and social support between genders, showing that men perceived it more than women. Additionally, it was identified that women with abstinence of more than a year have an increase in their sense of coherence and perception of social support when compared to those with less than one year. A regression analysis indicated that lack of social support was related to a state of anxiety and longer duration of abstinence in both sexes (Chen, 2010).

Tang et al. (2010) examined the relationship of social environment with health compromising behaviors - HCB among 6566 Chinese students ( 3777 boys and mean age of 14.67 years; $S D=1.00$ ). Students answered scales of physical abuse, affirmative school experience, social support and health compromising behaviors. Results indicated that the endorsement of HCB was $51.2 \%$ for licit drugs (alcohol and cigarretes) and $2.9 \%$ for illicit drugs. Abused students were more likely to practice HCB when they had low levels of social support than those who had high levels. Moreover, physical abuse was correlated with higher $\mathrm{HCB}$, suggesting that the perceived social support appear as a protective factor for compromising behaviors such as smoking, using illicit drugs and presenting self-harm behaviors.

Besides family aspects, literature establishes relationships between the use of alcohol and drugs with psychiatric comorbidities (Hermeto et al., 2010; Jané-Llopis \& Matytsina, 2006; Glantz et al., 2009; Palomo, Kostrzewa \& Beninger, 2007). It is known that drug abuse appears associated in individuals with severe mental disorders; however, it is difficult to establish a causal relationship between the presence of psychiatric symptoms and abuse of psychoactive substances. In most cases, it is not possible to determine if the substance led the subject to develop a mental disorder or are the symptoms of the disorder that motivate the individual to use psychoactive substances (Hofmann, Richey, Kashdan \& Mcknightt, 2009; Silva et al., 2009). A similar question is raised on the relationship between the use of alcohol and drugs with psychiatric symptoms, since the use of drugs can increase the severity of psychiatric disorders, in the same way that feelings of helpelessness and anxiety can increase drug use (Suchman, McMahon, Slade \& Luthar, 2005).

A research based on data from the National Comorbidity Survey Replication from the USA, with a sample of 9282 individuals, reported that anxiety disorders were associated with an increased on consumption of alcoholic beverages (Palomo et al., 2007). Glantz et al. (2009) for example, investigated the number of substance disorders that might be prevented by interventions on mental disorders and observed that treating people with mental disorders can minimize the public costs for treating substance dependence.

Silva et al., (2009) evaluated the implications of mood patterns in the maintenance of the drug abuse in users of crack, cocaine and alcohol abusers from a hospital specialized in treatment of chemical substance dependence. Results showed the presence of psychiatric comorbidity in $84 \%$ of the participants, 77.4\% met the criteria for mood disorder and $41.9 \%$ presented anxiety disorders. Another study also showed the presence of comorbidities in cocaine/crack and alcohol/crack for 32 patients admitted for detoxification and detected the presence of major depressive disorder in about $53 \%$ of cocaine/crack and approximately $67 \%$ of alcoholics/ crack users (Conger, 1956). 
This way, several studies pointed that psychiatric disorders can contribute to negative effects in treatment success and the negative impact that the use of maladaptive substances have on individuals and society, investigating ways to detect protective factors for drug use, as well as their interpersonal consequences, become valid. Yet, considering that family is pointed in some studies as an important factor to contribute to drug treatment, family assessment, as pointed by Teodoro (2006) is an important issue to a better comprehension about relationships of subject and family provided by culture. Thus, the present study sought to contribute to a better comprehension between the relationship of family and chemical dependence, aimed to estimate the degree of perception of family support in individuals in treatment for chemical dependence, and also to analyze relationships among the symptoms associated, in this case, levels of depression, anxiety and hopelessness.

\section{Method}

\section{Participants}

Data were collected with 130 participants, which had been admitted to treatment at least three months before in six specialized services for treatment of drug addiction. For this study, only the ones who answered more than 95\% of each test and met the criteria for alcohol abuse or dependence and/ or other drugs (cocaine, crack, cannabis, ecstasy, amphetamines and inhalants) of the DSM IV-TR (APA, 2002) were considered. Considering this criteria, the response rate was $74.61 \%$, and data was analyzed with 97 volunteers, aged 18 to 59 years old $(M=34.16 ; S D=10.94), 64.1 \%(n=$ 66) male, from six different private Brazilian institutions for treatments of drug addiction.

Of the participants, 59 (60.8\%) performed some type of psychological or psychiatric treatment, 26 (26.79\%) reported specific treatment for chemical dependency, 17 (17.52\%) alcoholism, 9 (9.28\%) panic disorder, 6 (6.18\%) depression and $1(1.03 \%)$ generalized anxiety disorder. About psychological treatment, $53 \%(n=35)$ of the males and $61.3 \%(n=19)$ used the service. The type of drugs used by patients is shown in Table 1.

Table 1

Type of drugs used divided by Male $(n=66)$ and Female $(n=31)$

\begin{tabular}{lllll} 
& \multicolumn{3}{c}{ Male } & \multicolumn{2}{l}{ Female } \\
& $\mathrm{f}$ & $\%$ & $\mathrm{f}$ & $\%$ \\
\hline Marijuana & 2 & 5,1 & - & - \\
Cocaine & 11 & 23,1 & 2 & 6,5 \\
Crack & 12 & 5,1 & 10 & 32,3 \\
Hashish & 1 & 10,3 & - & - \\
Alcohol & 12 & 17,9 & 8 & 25,8 \\
Mixed Drugs & - & - & 1 & 3,2 \\
Total & 38 & 42,4 & 21 & 67,7 \\
\hline
\end{tabular}

It can be observed in Table 1 that the type of drug most commonly used by both genders is crack, followed by alcohol and cocaine. Comparing the preferences of use, we could notice that women's preferences were similar to men's, except for the use of cocaine, which presented a low frequency of use. About the score of the instruments, it was observed that $66 \%$ $(n=64)$ participants showed levels of anxiety classified as low or moderate, $78 \%(n=74)$ levels between low and moderate depression and $60.8 \%(n=59)$ low levels of hopelessness. Of the subjects with severe scores, highlights the frequency of cases when assessed by BAI $(16.5 \%, n=16)$. In the other two instruments, the rate of severe scores was 1 (1\%).

\section{Instruments}

Criteria for substance or dependence abuse -DSM-IV-TR (APA, 2002). Checklist prepared by the authors containing 11 criteria for DSM-IV to determine presence of abuse or dependence on alcohol or other drugs.

Perception Inventory of Family Support (Baptista, 2009). It is a 42-item inventory that assesses the perception that the individual has about received support. It is a three-point scale divided into three dimensions, Consistent affective-F1 with 21 items that reflect questions that deal with the expression of affection among family members; Family Adaptation-F2 with 13 items that refer to negative feelings and behaviors toward family and Family Autonomy -F3 with 8 items, which has issues that can signal relationships of trust, freedom and privacy among the members of a family. The inventory's total sum resulted a Cronbach's alpha of 0.93, and the higher the score the better the support that the individual perceives.

Beck Depression Inventory - BDI (Cunha, 2001). Version translated and validated to the Portuguese language, being a self-report scale, used to assess and quantify the intensity of depressive symptoms, consisting of 21 items with four answer choices, ranging from zero to three. The classification of severity of depression varies from minimal depression, mild, moderate and severe. In the Brazilian version, the Cronbach's alpha was of 0.79 and 0.82 in psychiatric and in non-psychiatric populations.

Beck Hopelessness Scale - BHS (Cunha, 2001). A selfreport scale consisting of 20 items that should be classified as true or false by the subject. Scores range from 0 to 20 , and the higher the score, the greater the hopelessness. In the Brazilian version, the Cronbach's alpha was 0.88 in psychiatric populations and similar the original version in non-psychiatric populations, indicating that the items of the Portuguese version of the BHS were homogeneous for both populations (Beck, Steer \& Garbin, 1988).

Beck Anxiety Inventory - BAl (Cunha, 2001). Consists of a self-report scale containing 21 items, in which the individual must refer to a four-point scale the level of symptom severity. The total score ranges from 0 to 63 , and allows verification of the intensity level of anxiety and the anxiety level is rated as least mild, moderate or severe. In Brazilian version, this instrument obtained alpha Cronbach of 0.90 in psychiatric and non-psychiatric populations. 


\section{Procedures}

This study was approved by the Ethics Committee in Research of Federal University of São Paulo (process: USP \# 3006/06) and collected between September to December 2010 in Santos/ SP/ Brazil, three exclusively for women and three exclusively for men. After the approval of the institutions and participants, through the Term of Consent, data was collected on 60 days, at intermittent intervals. The locals of application were selected by convenience, due to the low number of consent of the institutions contacted. The assessment instruments were delivered to each volunteer to answer in a single session (cross sectional), and the order of application varied in order to control bias of fatigue in the filling. A research assistant explained how to respond instruments of self-fulfillment, emphasizing that there were no right or wrong answers and that responses would be kept anonymous. There was a set time limit for participants to respond to the instruments (40 minutes).

\section{Statistical analysis}

In order to analyze relations between the constructs, the Pearson's correlation coefficient, and regression analysis were performed. Comparison between the genders, are accessed by the $t$ test for nominal variables, and ANOVA for ordinal variables. In all cases, results were considered significant if $p$ $<0.05$ (Morais, 2007).

\section{Results}

First, considering the descriptive data, a mean difference analysis was performed considering the descriptive data from years of drug use, frequency of use, age and score on the instruments. Results are in Table 2.

Table 2 shows that, of the variables, the only one that showed a statistically significant difference in frequency of drug use, indicating that the time of drug use was significantly higher in men. Furthermore, there were no statistically significant differences in the mean scores of any of the instruments applied. In addition, correlational analysis were performed in order to verify the relationship between the instruments. Table 3 shows the correlations obtained.

Table 3 shows the results observed in the correlations between the perception of family support received and the symptoms of depression, anxiety and feelings of hopelessness. As it can be seen, the total IPSF was negatively related with $\mathrm{BDI}$ and $\mathrm{BAI}$, indicating that the better the perception of family support, the more reduced their symptoms are. Besides, out of the 12 possible correlations, five were statistically significant, but all weak ${ }^{28}$. These correlations indicated that the results of the factor family autonomy with hopelessness, affection and total IPSF factor with BDI and BAI were not found randomly.

In addition, other statistical tests were performed, as a linear regression analysis to verify if perception of family support can influence hopelessness, anxiety and depression. Therefore, the IPSF as dependent variable, and results are indicated on Table 4.
Table 2

Mean difference by Student $t$ test for the sexes in relation to years and number of drug use and age measured by Beck scales and the IPSF

\begin{tabular}{|c|c|c|c|c|c|c|c|}
\hline & Sex & $\mathrm{N}$ & Mean & SD & $\mathrm{t}$ & $d f$ & $\mathrm{p}$ \\
\hline \multirow{2}{*}{ Years using drug } & Male & 35 & 15,63 & 4,34 & \multirow{2}{*}{$-0,333$} & \multirow{2}{*}{54} & \multirow{2}{*}{0,741} \\
\hline & Female & 21 & 16,05 & 4,91 & & & \\
\hline \multirow{2}{*}{ Frequence of use } & Male & 39 & 6,79 & 1,40 & \multirow{2}{*}{2,558} & \multirow{2}{*}{58} & \multirow{2}{*}{0,013} \\
\hline & Female & 21 & 5,62 & 2,15 & & & \\
\hline \multirow{2}{*}{ Age } & Male & 66 & 33,97 & 11,19 & \multirow{2}{*}{$-0,255$} & \multirow{2}{*}{95} & \multirow{2}{*}{0,799} \\
\hline & Female & 31 & 34.58 & 10,57 & & & \\
\hline \multirow{2}{*}{ BAl Tot. } & Male & 66 & 16,29 & 12,03 & \multirow{2}{*}{0,267} & \multirow{2}{*}{95} & \multirow{2}{*}{0,790} \\
\hline & Female & 31 & 15,58 & 12,51 & & & \\
\hline \multirow{2}{*}{ BHS Tot. } & Male & 66 & 3,91 & 2,65 & \multirow{2}{*}{$-1,104$} & \multirow{2}{*}{95} & \multirow{2}{*}{0,272} \\
\hline & Female & 31 & 4,58 & 3,09 & & & \\
\hline \multirow{2}{*}{ BDI Tot. } & Male & 66 & 13,70 & 9,18 & \multirow{2}{*}{0,464} & \multirow{2}{*}{95} & \multirow{2}{*}{0,644} \\
\hline & Female & 31 & 12,74 & 10,02 & & & \\
\hline \multirow[b]{2}{*}{ IPSF F1 } & Male & 66 & 20,60 & 8,64 & \multirow[b]{2}{*}{$-0,160$} & \multirow[b]{2}{*}{95} & \multirow[b]{2}{*}{0,873} \\
\hline & Female & 31 & 20,90 & 8,26 & & & \\
\hline \multirow{2}{*}{ IPSF F2 } & Male & 66 & 14,15 & 4,68 & \multirow{2}{*}{0,812} & \multirow{2}{*}{95} & \multirow{2}{*}{0,419} \\
\hline & Female & 31 & 13,26 & 5,78 & & & \\
\hline \multirow{2}{*}{ IPSF F3 } & Male & 66 & 8,89 & 3,34 & \multirow{2}{*}{0,071} & \multirow{2}{*}{95} & \\
\hline & Female & 31 & 8,84 & 4,06 & & & 0,944 \\
\hline & Male & 66 & 43,7 & 13,62 & & & \\
\hline IPSF TOT & Female & 31 & 43,0 & 14,60 & 0,215 & 95 & 0,831 \\
\hline
\end{tabular}

IPSF- Family support perception inventory F1 Consistent affective; F2 Familiar adaptation; F3 Family autonomy; BAI: Beck Anxiety Inventory; BHS: Beck Hopelessness Inventory.

Table 3

Pearson's correlation coefficient ( $r$ ) to the variables IPSF, BDI, BHS e $B A I$.

\begin{tabular}{lllll}
\hline & F1 & F2 & F3 & Total \\
\hline BHS & $-0,128 \#$ & $0,008 \#$ & $-0,216^{*}$ & $-0,131 \#$ \\
BDI & $-0,232^{*}$ & $-0,168 \#$ & $-0,167 \#$ & $-0,246^{\circ}$ \\
BAI & $-0,336^{*}$ & $-0,197 \#$ & $-0,125 \#$ & $-0,309^{*}$ \\
\hline
\end{tabular}

${ }^{* *} p<0,005 ;{ }^{*} p<0,05 ;$ \# NS $(p>0,05)$

F1 Consistent affective; F2 Familiar adaptation; F3 Family autonomy; BDI: Beck Depression Inventory; BAI: Beck Anxiety Inventory; BHS: Beck Hopelessness Inventory.

Table 4.

Regression analyzis of IPSF $(x)$ as associated with BAI, BDI and BHS (y)

\begin{tabular}{lllll}
\hline & R square & beta & $\mathrm{t}$ & $\mathrm{p}$ \\
\hline BAl & $96 \%$ & $-0,31$ & $-3,16$ & $0,002^{* *}$ \\
BHS & $17 \%$ & $-1,31$ & $-1,30$ & $-0,200 \#$ \\
BDI & $61 \%$ & $-0,25$ & $-2,47$ & $0,015^{*}$ \\
\hline
\end{tabular}

${ }^{*} p<0,005 ;{ }^{*} p<0,05 ;$; NS $(p>0,05)$

F1 Consistent affective; F2 Familiar adaptation; F3 Family autonomy; BDI: Beck Depression Inventory; BAI: Beck Anxiety Inventory; BHS: Beck Hopelessness Inventory. 
Results of the regression analysis indicated that family support correlated with the level of anxiety and depression, at a level inversely proportional in an equation representing respectively $96 \%$ of the variance of $\mathrm{BAI}$ and $61 \%$ of the variance of the BDI. Regarding BHS, it was found that family support was not able to predict the increase in this variable.

\section{Discussion}

Different institutions and social groups consider the maladaptive use of drugs as one of the most serious public health problems, accompanied by individual, family and society costs (Herman \& Petersen. 1996; Glantz et al., 2009). As discussed, one of the possible risk/ protective factors is family support (Herman \& Petersen, 1996; Kumpfer et al. 2003; Paiva \& Ronzani, 2009; Rodriguez, 2003). For this reason, this study aimed to analyze the relationship among depression, anxiety, hopelessness and perceived family support in individuals with treatment for chemical dependence. The results are discussed below.

The correlational analysis showed a negative relationship between the constructs, but only five were statistically significant, indicating that the level of hopelessness was related to family autonomy, whereas levels of depression and anxiety with family affection and total perception of family support. Different from the expected, not all correlations were significant, and correlations were weak. Thus, a regression analysis was performed to observe to what extent family support could predict the symptoms measured by the Beck scales, which showed that family support is an important predictor of levels of anxiety and depression in this study.

These results are according to Tang et al., (2010) who observed social support as a protective factor for behaviors such as smoking and using illicit drugs. Paiva and Ronzani ${ }^{3}$ found that most negligent family styles tended to be related to the potential use of drugs. On the other hand, drug use also appears as a factor associated to the way people interpret the received support ${ }^{7}$. For example, Hermeto et al. (2010) found that drug abusers' mothers have more descriptions of a non-supportive family, without rules, with conflict and neglect. As already discussed, in this study other factors that could influence the relationship of family support and mental disorders, as friends, for example, were not controlled (Pardo et al., 2006; Rodriguez, 2003), so these results must be interpreted with caution.

Concerning the presence of psychiatric disorders, results showed that more than a half of the sample had clinically significant symptoms of comorbidities. In this way, studies about comorbidity among psychiatric disorders showed that drug use appears as a risk factor for developing psychiatric disorders, but again, are inconclusive in regard to how this relationship is (Conger, 1956; Hofmann et al., 2009; JanéLlopis \& Matytsina, 2006; Suchman et al., 2005; Tang et al., 2010).

It was found that there were no main differences statistically significant when comparing genders, except for the variable frequency of drug use, which women showed a lower frequency of use. As pointed by Glantz et al. (2009), Jané- Llopis and Matytsina
(2006) among others, mental diseases are recurrent complaints of this population and should be considered that they may develop clinical symptoms during the beginning, after or before using drugs, but this variable are not controlled in this study because the institutions did not authorize a complete evaluation of diagnosis and comorbidities justifying that only their own psychiatrists could do that, and these evaluations are not disclosed to researchers, suggesting the need for further studies with this control.

Instead, considering that mental disorders can result in a distorted view about yourself, how interpret their actions and the action of another, distortions of thought can be considered as a sponsor of mental disorders (Beck, Rush, Shaw \& Emery, 1982). In this case, we can consider that the perception that the patient reports on family support has a direct influence on the way in which they interpret their world, themselves and each other.

Furthermore, commenting on the presence of psychopathological symptoms, the prevalence of anxiety symptoms observed in this study was similar to the results in the research of Silva et al. (2009) while the proportion of individuals with significant symptoms of depression was less than those reported by the same study. Thus, the results are consistent with the idea of high prevalence of psychiatric comorbidity among substance dependence, once that almost half of the sample investigated in this study had significant symptoms of depression and / or anxiety.

\section{Conclusion}

The results of this study are consistent with the data available in the literature and demonstrate the need to assess comorbidities related to maladaptive pattern of psychoactive substances. Moreover, results show that family relationships must be considered both in the development of preventive programs and the treatment of drug abuse, since such factors can interfere in the involvement with psychoactive substances.

Considering that the main objective of this study was to verify the relationship between perception of family support with psychiatric symptoms using psychometric tests, limitations of the study must be discussed. We consider that social support, as family, can contribute to the adherence of treatment and recovery, thus, one of the considerations for further studies is the use of tests that evaluate the perception of support provided by parents, and also the importance of family support to the patient and how they judge that family involvement can assist them. Still, it is recommended for further studies to assess family characteristics associated, such as frequency of visit, family history, and drug use by other members.

Finally, another limitation was the number of participants who agreed to take part in the study, and the response rate, which has considerably decreased the amount of valid data. For further studies, we suggested investigating variables such as the reason for drug use, duration of use and number of hospitalizations. Finally we suggest controlled studies to comprehend the relationship between family and mental disorders and a sample with larger size. 


\section{Conflicts of interest}

There is no conflict of interest to declare.

\section{References}

American Psychiatric Association (2002). Manual Diagnóstico e Estatístico de Transtornos Mentais. Trad. Cláudia Dornelles. (4ª ed. rev.). Porto Alegre: Artmed.

Baptista, M.N. (2009). Inventário de Percepção de Suporte Familiar- IPSF. Manual Técnico. São Paulo: Vetor.

Beck, A. T., Rush, A. J., Shaw, B. F., \& Emery, G. (1982). Terapia Cognitiva da Depressão. Rio de Janeiro: Zahar.

Beck, A.T., Steer, R.A. \& Garbin, M.G. (1988). Psychometric properties of the Beck Depression Inventory: Twenty-five years of evaluation. Clinical Psychology Review, 8, 77-100.

Botella, H.C. (2007). Redes de apoyo para la integración social: La familia. Salud y Drogas, 7, 45-56.

Brasileiro, R de F., Jablonski B. \& Féres-Carneiro T. (2002). Papéis de gênero, transição para a paternindade e a questão da tradicionalização. Psico, 33, 289-310.

Chen, G. (2010). Gender differences in sense of coherence, perceived social support, and negative emotions among drug-abstinent Israeli Inmates. International Journal of Offender Therapy and Comparative Criminology, 54, 937-958.

Conger, J.J. (1956). Alcoholism: theory, problem and challenge II reinforcement theory and the dynamics of alcoholism. Quarterly Journal of Study on Alcohol, 17, 296-305.

Cronkite, R.C. \& Moos, R.H. (1984). Sex and marital status in relation to the treatment an outcome of alcoholic patients. Sex Roles, 11 , 93-112.

Cunha, J.(2001). Manual da versão em português das escalas Beck. São Paulo: Casa do Psicólogo.

Glantz, M.D., Anthony, J.C., Berglund, P.A., Degenhardt, L., Dierker, L., Kalaydjian, ..., Kessler, R.C. (2009). Mental disorders as risk factors for later substance dependence: estimates of optimal prevention and treatment benefits. Psychological Medicine, 39, 1365- 1377.

Hanson, M.D. \& Chen, E. (2007). Socioeconomic status and substance use behaviors in adolescents: the role of family resources versus family social status. Journal of Health Psychology, 12, 32-35.

Hawkin, J.D., Arthur M.W. \& Catalano, R.F. (1998). Preventing substance abuse. Crime Justice, 8, 197- 277.

Herman, S.M., \& Petersen, A.C. (1996). The protective role of coping and social resources for depressive symptoms among young adolescents. Journal of Youth and Adolescence, 25, 733-753.

Hermeto, E.M.C., Sampaio, J.J.C. \& Carneiro, C. (2010). Abandono do uso de drogas ilícitas por adolescente: importância do suporte familiar. Revista Baiana de Saúde Pública, 34, 639-652.

Hofmann, S.T., Richey, J.A., Kashdan, T.B. \& Mcknight, P.E. (2009). Anxiety disorders moderate the association between externalizing problems and substance use disorders: data from the National Comorbidity Survey Revised. Journal of Anxiety Disorders, 23, 529-534.

Jané-Llopis, E. \& Matytsina, I. (2006). Mental health and alcohol, drugs and tobacco: a review of the comorbidity between mental disorders and the use of alcohol, tobacco and illicit drugs. Drug and Alcohol Review, 25, 515-536.

Kumpfer, K.L., Alvarado, R. \& Whiteside, H.O. (2003). Family-based interventions for substance use and misuse prevention. Substance Use \& Misuse, 38, 1759-1787.

McFarlane, A.H., Bellissimo, A. \& Norman, G.R. (1995). Family structure, family functioning and adolescent well-being: the transcendent influence of parental style. Journal of Child Psychology Psychiatry, 5, 847-64.

Morais, P.R. (2007). Estatística para Psicólogos (que não gostam de números). $1^{\text {a }}$ ed. Santo André, São Paulo: ESETec Editores Associados. 155p.

Paiva, F.S. \& Ronzani, T.M. (2009). Estilos parentais e consumo de drogas entre adolescentes: revisão sistemática. Psicologia em Estudo, 14, 177-183.

Palomo, T., Archer, T., Kostrzewa, R.M. \& Beninger, R.J. (2007). Comorbidity of substance abuse with other psychiatric disorders. Neurotoxicity Research, 12, 17-27.

Pardo, M.E., Pineda S., Carrillo, S. \& Castro, J. (2006). Análisis psicométrico del Inventario de Apego con Padres y Pares en una Muestra de Adolescentes Colombianos. Revista Interamericana de Psicología, 40, 289-302.

Rodriguez, J.A.G. del C. (2003). Familia y drogas: aspectos psicosociales. Revista Internacional de Ciencias Sociales y Humanidades, 13, 13-163.

Schenker, M. \& Minayo, M.C. de S. (2004). A importância da familia no tratamento do uso abusive de drogas: uma revisão da literatura. Cadernos de Saúde Pública, 20, 649-659.

Silva, C.R. da, Kolling, N. de M., Carvalho, J.C.N., Cunha,S.M.; \& Kristensen, C. H (2009). Comorbidade psiquiátrica em dependentes de cocaina/crack e alcoolistas: um estudo exploratório. Aletheia, 30, 101-112.

Suchman, N.E., McMahon, T.J., Slade, A. \& Luthar, S.S. (2005). How early bonding, depression, illicit drug use, and perceived support work together to influence drug-dependent mother's caregiving. American Journal of Orthopsych, 75, 431-435.

Tang, C.S., Wong, W.C.W., Leung, P.M.S., Chen W., \& Ling, D.C. (2010). Health compromising behaviors among Chinese adolescents: role of physical abuse, school experience, and social support. Journal of Health Psychology, 16, 457-466.

Teodoro, M.L.M. (2006). Afetividade e conflito em diades familiares: avaliação com o familiograma. Revista Interamericana de Psicologia, 40, 385-390.

Weisner, C. (1993). Toward an alcohol treatment entry model: a comparison of problem drinkers in the general population and in treatment. Alcohol Clinical and Experimental Research, 17, 746-752. 